of which is a subject of much difference of opinion, will be more clearly elucidated.

Many, and-most opposite opinions, have been advanced, both by English and foreign authors, on the source from whence the above fluid, constituting the disease termed "pyrosis," is derived. According to Cullen's view, it depends on spasm of the muscular fibres of the stomach, which, being communicated to the blood ressels and exhalants, determines an increased quantity of fluid in them, at the same time increasing its impetus, whilst constriction taking place in their extremities, the watery parts only of the blood are allowed to be poured out. An opposite view has been taken by Mason Good, viz., that pyrosis may be often induced by a peculiar irritability of the proper absorbents of the stomach. Some autbors believe it to arise from the mucous follicles of the stomach and duodenum, whilst others consider its source to be the spleen. In the case above narrated, Cullen's view, with some modifications, appears to be best supported; that is, such an extensive abraded surface as has been described, must have exposed the extremities of innumerable nerves, and capillaries and other vessels. On taking solid food, and, at times, from mental and other causes, their extremities must have been subjected to excessive irritation, increased by the natural vermicular action of the muscular coat of the stomach, to effect the purpose of due digestion and expulsion. This irritation would cause contraction and constriction of the terminations of the exposed vessels, allowing only the more minute and watery portions of the blood to exude,-something analogous to the serous discharge which is immediately poured out on part of the epidermis being forcibly grated off.

The treatment recommended for pyrosis has been, from its obscure pathology, necessarily very empirical, some practitioner's recommending alkalies, others opiates, and others astringents. In the case before us the first indication would be to allay irritation,-me second, to check the ulcerative process, and induce a natural and healthy surface on the mucous membrane. The first would appear to be accomplishable by enforcing a very spare and fluid bland diet, such as milk-and-water, thin gruel, arrowroot, \&c., which would produce little, if any, vermicular action of the muscular fibres of the stomach. The second indication would be best attained by leeching and fomentations, applying counter-irritants, such as ung. ant. tart., \&c., to the epigastrium, thus establishing a diverticulum to diseased action, and removing that subacute gastritis which was, most probably, the original source of the disease. Medicines by the mouth it would, perhaps, be better altogether to omit, exhibiting instead enemas of warm water, medicated, if required, by circumstances, Astringents, which some au thors have reconmended, would, it is er. dent, in the above ease, only hare increased the disease, and opiates would have oiscured the symptoms, and the disease would have progressed so long as its cause continued. The perforation was; no doabt, the result of the gradual uncontrolled progress of the ulcerative-process, which, by an ap. propriate treatment, may have liealed just the same as if it had occurred in any other organ.

C ASE OF

\section{FRACTURE OF THE FEMUR,}

\author{
SUCCESSFULY TRFATED ON THE
}

\section{SPLINTLESS METHOD.}

By Jo.tN Johnstow Kelso, M.D., Lishurn.

Sarah Phillips, ætatis 4 , whilst anusing herself with some companions, on the 10 th of October, received a fall from a cart, Some time afterwards $I$ saw her, and found that she had got an oblique fracture of the femur, about the junction of the lower two. thirds of this bone with the upper third. There existed considerable tumefaction, with some pain about the seat of injury, the effect of riolence inflicted by one of the relatives of the child, who, mistaking the real nature of the accident, had emplojed rather forcible traction of the limb. Having re. duced the fracture, the extremity was laid on a pillow, stuffed with finely-carded tow, on which the eighteen-tailed bandage had been previously placed. The tails of the bandage having been lapped around the thigh, of a moderate tightness, there was then applied two thin slips of wood, of about ten inches long and two broad, as a set.off against splints, which are considered by the people as indispensable. These having been bedded with tow, so as to defend from their contact the immediate seat of injury, they were bound down at either end by tapes. Finally, the edges of the pillow were drawn a little up towards the sides of the extremity, by bands of calico, and so adjusted underneath by padding as to bring the limb to that easy bent position in which the muscles are most relaxed.

Second day.-The limb is much swelled, hot, and very painful, more especially about the seat of fracture, accompanied with general restlessness, and impatience of confinement, on the part of the child. It is thus extremely difficult to preserve any thing like quietude in the injured part. The superacetate of lead lotion is to be assiduousity applied to the limb.

Fifth day.-Circumstances, over which I had no controul, prevented me from visiting my little patient till to-day, when I with 
regret discovered that things had not gone on so farourably as my anticipations had led me to expect. It is true, the tumefaction, heat, and pain have, in great measure, subsided, but the fracture is displaced, the extremities of the bone are riding upon each other, and the limb quite crooked. This state of things arose from the foot having slided off the edge of the pillow during the tossings of the child, without being replaced. The fracture was again reduced, and the limb put up as before, charge being given, at the same lime, to the immediate attendants on the child, to preserve the limb as nearly as possible in the same position in which it was now left.

Sixteenth day.--Since the date of the last report the fracture has rapidly progressed topards complete re-union, in the absence of all local pain or uneasiness. The callus is now so firm as to allow the little patient to elerate its limb from the pillow on which it reposes, and even to throw it about playfully. But in order to guard against unnecessary or rash movements, until the callus becomes more firm, I thought it prudent to apply to the extremity a rather long piece of slender wood, with a circular roller, as a precautionary measure against any untoward accident which, in some of the child's playful moods, might otherwise possibly befall it.

Remarls.-This case affords another convincing example in favour of the method advocated by Mr. Radley in the rreatment of fractures. And when we reflect how frequently these accidents occur, and the greater or less sufferings which they usually excite, no one can view with indifference the proposal of a method of treatment recommended so powerfully by its simplicity, and its freedom from producing local pain or uneasiness, contrasting strongly, as it does, with - the common practice of the day, as sanctioned by the greatest names which adorn the profession, both in this and other countries.

The case, also, I am inclined to believe, possesses some additional interest, from the circumstance of its occurring in so young a subject, who, with more than the ordinary restlessness of habit of its years, and devoid of judgment in regard to the right rules of management, which should have been implicitly adhered to, was, it will be conceded, peculiarly ill adapted for being the subject of experiment. Add to this the general and reprehensible negligence evinced on the part of the nearest relatives of the child, and our wonder at the successful termination of the case will be not a little increased. In proof of the justness of what I have been now stating, I may merely allude to the fact of the palpable displacement of the fracture, and the evident crookedness of the member, on the fifth day of the accident, - a state of matters which was, in some degree, antici- pated, from the feverish excitement and rest. lessness of the child, but which might, I think, have been easily counteracted by proper attention to that right management which the circumstances of the case so imperiously demanded. Nor was any the least intimation given to me on the subject of the occurrence. It would be wholly unnecessary to remark,-were it not to anticipate an objection which may possibly be urged against the adoption of a practice that demands the closest observation, opposed, as it may be considered to be, to any such inconvenience attending the one in common use, - that in country practice, however urgent the case may happen to be, professional visits must be always irregular. This objection, however plausible it may at first view appear, only holds good, if, indeed, it can hold at all, in those cases where the subjects of the accident in question are of so tender an age, as not to possess understanding; for individuals of maturer years, enlightened by reason and experience, will hardly fail to afford to their case the necessary attention, under a system of treatment which dispenses with a farrago of surgical apparatus, relieves them from a greater or less amount of painful sufferings, and, as a limited experience would seem to prove, expedites considerably the cure.

It will be observed that on the sixteenth day from the receipt of the injury, and on the eleventh from the second reduction of the fracture, the callus was so firm as to allow the little patient to move about the limb pretty freely. And after the tumefaction and pain which had been induced at first by the gross violence to which the injured thigh was subjected, had once fairly subsided, there occurred nothing afterwards to impede the rapid progress of the cure.

In effecting union of fractures, there are three essential elements, viz., rest, correct position, and a particular quantity of constitutional energy, so as to be capable of deter. mining a relative amount of local reparative action.

Every one is aware of the good effects of rest, more especially in the earlier stages, in favouring ossific union; and whether this be broken in upon by general restlessness on the part of the patient, or, what is infinitely more common, by local irritation, from one or more causes, exciting to more or less muscular action in the injured limb, the effects are equally injurious. The recognition of this important principle is com paratively modern, and undoubtedly constituted a new era in surgical science. But we are mainly indebted to Mr. Pott for his eloquent advocacy of the great utility of complete quietude in the treatment of the accidents in question. And since the amount of repose was discovered to bear a certain and fixed ratio to muscular relaxation, the 
question naturally arose in the mind of Mr. Pott, whether it was not possible to effect complete relaxation of all the muscles of an extremity, by placing it in the easy bent posture? Advocating, however, as the great English surgeon did, the affirmative of this question, the generality of the profession are justly opposed to such a doctrine; but all concur in believing that the greatest possible relaxation of all the muscles results from that position in which the extremity is moderately semifiexed, the thigh upon the pelvis, and the leg upon the thigh. Holding, then, in view this important principle, it is matter at once of surprise and regret, that it should not have been earlier turned to account in the treatment of fractures; for the method promulgated by Dessault, preferred, as it almost universally is, in France, and pretty generally adopted in these countries, is, confessedly, based upon the principle of coercing or restraining muscular action, the arowedly great opponent of ossific union, by a mechanical apparatus. A little reflection, however, must have shown that this practice, which I, too, have occasionally adopted, is better calculated to dis. play the triumph of surgical genius than the piomotion of the curative efforts of nature by scientific means, and with reference to ease. It is both difficult and painful, to a greater or less extent, to subdue muscular power, not to mention the insuperable inconvenience of the most approved mechanism by which that end may be attained. Besides, reasoning, a priori, would lead us to expect what experience goes to confirm, that those muscles which are thus subjected to a species of coercion or torture, are much longer in regaining their wonted activity than if they had been reposing all the while, under the placid system of relaxation.

True it is, we have the fracture apparatus of Sir C. Bell, and the real improvement upon that by Mr. Earle, by which the limb may be retained in the easy bent position, during the process of curation. 'his was certainly an important improvement, not as regards simplifying the surgical apparatus, but by relieving the patient from the indescribable uneasiness of the straight posture of the limb, for an indefinite length of time, and the greater or less sufferings from continued extension. In this method short splints are only admissible. An able reviewer, in the October number of $\mathbf{D r}$.Johnson's Review, has defined " short splints applied only to the thigh, as not being treatment with splints," and there can surely accrue nothing of disadvantage, to say the least of it, in abandoning them altogether; and as there can be no magic in the wood on which the limb reposes, any more than in the pillow, the innovation of the pillowy method must surely be invaluable, as being so much more congenial to the sensations of the patient.

Next in importance to rest, is the appo- sition of the extremities of the fractured bone; and it is a well-ascertained fact, that the more correct the apposition is, the union is effected not only more speedily but more solidly. The fracture having been properly reduced, the reaptation can only be dis. turbed through the agency of the muscles; and if these organs can be invited to repose, as it is admitted they may be, by an appro. priate system of management, such a pro cedure will surely be preferable to one ope. rated through the agrency of physical force.

With regard to constitutional energy, I have to remark, that we are sufficiently con. yersant with the principal phenomena cha. racteristic of the state of system to which the above conventional term is applicable, although we are completely ignorant of the real amount of vigour absolutely necessary to the perfecting of ossific union. Frac. tures, it is well known, unite with different degrees of celerity, under circumstances, s0 far as external appearances are concerned, very nearly the same, and there are peculiar states of the system, besides those generally admittted, which effectually oppose the re. parative act altogether. Were it even pos. sible to ascertain the cause, or series of causes, which lead to such results, the newly-acquired knowledge might, perhaps, prove of but trifling advantage ; but nanage. ment, both general and local, has, I all satisfied, more to do in these cases than is generally believed. And in cases of now union, I am equally convinced that there is generally too much attributed to defective constitutional vigour, \&c., and too little at. tention paid to those minor, more trivial, indications, which legitimately fall within the province of surgical art. In proof of the correctness of what has here been asserted, I could adduce, were it necessary, some cases in point, from personal observation; and, in conclusion, $I$ would observe, that whatever method of treatment the prac. titioner, in his judgment, may choose tw adopt, the more insignificant (unsurgical, if you please), points of management should not be overlooked, in his eagerness to ap. proach to absolute perfection in the more prominent and strictly surgical.

Lisburn, Nov. 13, 1836.

\section{CASES OCCURRING IN SURGICAL PRACTICE.}

\section{To the Editor of ThE LANCET.}

SIR :-Conversing, lately, with a fer medical friends on subjects connected will our profession, I happened to mention som cases which had occurred to me during m! residence at Bantry, of which the followini appeared to them to be sufficiently interest ing to merit a place in your journal. I therefore, take the liberty of requesting yol 